\title{
Slippery FACTs: The Rise of a "mandated" Animal Welfare Science
}

By 1975, scientific engagement with animal welfare had come a long way since Animal Machines. In 1973, ethology's status had been given a significant boost with the award of the Nobel Prize in Physiology or Medicine to Konrad Lorenz, Niko Tinbergen, and Karl von Frisch for "their discoveries concerning organization and elicitation of individual and social behaviour patterns." Meanwhile, earlier taboos about studying animals' affective states were falling as a result of the retirement of first-generation ethologists and a wider reorientation of the discipline. In Britain, younger researchers were beginning to apply behavioural findings to farms, and a new discipline of animal welfare science was emerging out of ethology and the veterinary sciences. From the beginning, this new discipline was a "mandated science." With regulators, activists, and producers all trying to define welfare, researchers were supposed to set 'objective' standards and profited from a resulting increase of funding. ${ }^{3}$ Defining standards proved difficult. The Brambell Committee had made important proposals for improving animal welfare. However, there was still much uncertainty about how to define and measure welfare and how to turn resulting

1 “The Nobel Prize in Physiology or Medicine 1973", The Nobel Prize, https://www. nobelprize.org/prizes/medicine/1973/summary/(20.05.2020).

${ }^{2}$ David Fraser, "Understanding animal welfare," Acta Veterinaria Scandinavica 50 Supl (2008), 6 .

${ }^{3}$ Robert Kirk, "The Invention of the 'Stressed Animal'," 241-263.

(C) The Author(s) 2021

C. Kirchhelle, Bearing Witness, Palgrave Studies in the History of

Social Movements, https://doi.org/10.1007/978-3-030-62792-8_10 
findings into practical rules: how much stress was acceptable? How should adequate diets be defined? How much water did a cow require? Initial hopes for easily quantifiable welfare markers soon proved misguided. Although researchers continued to emphasise that measuring welfare was possible, ${ }^{4}$ resulting methodologies and experimental setups were influenced by disciplinary preferences, contemporary value struggles, and target-oriented funding from sponsors like the RSPCA and Ruth Harrison.

\section{A New Kind of Science: The Rise of Animal WELFARE SCIENCE}

In the decade following the 1965 Brambell Report, three different approaches to assessing welfare emerged: (1) a first approach evaluated classic physiological indicators of animals' basic health and biological functioning, (2) a second approach employed a mix of physiological and behavioural methods to study how animals 'cope' with farm environments; and (3) a third approach focused on the 'naturalness' of different production systems. ${ }^{5}$

Veterinary scientists were among the first to engage with farm animal welfare research. The discipline's engagement is unsurprising given veterinarians' traditional role as guardians of animal health, close ties to the agricultural industry, and parallel calls for preventive veterinary health services in Britain. ${ }^{6}$ Their alignment with the productivist paradigm of postwar agriculture guaranteed veterinary researchers a full hearing in ministries and committees like FAWAC. It also made many early veterinary researchers focus less on behavioural and more on quantifiable physiological welfare measures with which to optimise intensive systems. ${ }^{7}$ For example, 1960s' research by Swedish veterinarian Ingvar Ekesbo studied blood calcium levels and teat injury frequency to assess different dairy cow systems. ${ }^{8}$ Measuring physiological indicators of stress was deemed particularly important. While much of early stress research was later criticised as

\footnotetext{
${ }^{4}$ Donald M. Boom, “A History of Animal Welfare Science,” Acta Biotheoretica 59 (2011), $127-137$.

${ }^{5}$ Buller and Roe, Food and Animal Welfare, 31-35.

${ }^{6}$ Woods, "Is Prevention Better Than Cure?".

${ }^{7}$ Woods, "Cruelty to Welfare," 19-20; Marian [Stamp] Dawkins, Animal Suffering. The Science of Animal Welfare (London and New York: Chapman and Hall, 1980), 109-111.

${ }^{8}$ Ingvar Ekesbo, "Disease incidence in tied and loose housed dairy cattle and causes," Acta Agriculturae Scandinavica 15 (Suppl) (1966), 1-74.
} 
simplistic, ${ }^{9}$ increasingly sophisticated models evolved during the 1970s. For a while, this raised hopes that husbandry systems could be evaluated by precise measurements of cytokine, corticoid, and other hormone levels in animals' blood. Health was thought to be the opposite of stress, whose ultimate manifestations were disease and death. ${ }^{10}$ According to veterinary researcher and FAWAC member David Sainsbury, "good health" was the "birthright" of every animal: "If it becomes diseased we have failed in our duty to the animal and subjected it to a degree of suffering that cannot be readily estimated." 11

While early veterinary welfare research provided important insights for the design of husbandry systems, its alleged overemphasis on physiological markers was criticised by other disciplines. The early 1970s saw a growing number of ethologists follow the example of W. H. Thorpe and study farm animal behaviour as an indicator of welfare. ${ }^{12}$ This engagement was in part a continuation of post-war shifts towards acknowledging animals' affective states and in part a response to new funding opportunities. ${ }^{13}$ It also accelerated the fragmentation of classic ethology.

Now described as a "lost discipline," 14 classic ethology reached the pinnacle of its international visibility in the 1960s and early 1970s. Despite ongoing resistance by Lorenz, the late 1950s had seen earlier 'hydrological' models of behaviour abandoned in favour of development- and ecology-oriented models. In 1963, Tinbergen made his last major theoretical contribution to ethology with his four whys (function, phylogeny, mechanism, and ontogeny) to animal behaviour. ${ }^{15}$ Around the world, there were now dedicated ethological journals, conferences, and centres of learning. In public, prize-winning documentaries by Tinbergen and the

\footnotetext{
${ }^{9}$ David Fraser, "Biology of Animal Stress. Implications for Animal Well-being," Journal of Applied Animal Welfare Science 2/2 (1999), 157-159.

${ }^{10}$ David Fraser, Understanding Animal Welfare. The Science in Its Cultural Context (Oxford: UFAW, 2008), 122-123; Robert Kirk, "Invention of the 'Stressed Animal'," 255-258.

${ }^{11}$ David Sainsbury, Farm Animal Welfare. Cattle, Pigs and Poultry (London: Collins, 1986); David Fraser, "Understanding Animal Welfare," Acta Veterinaria Scandinavica 50 (supplement 1), S 2 .

${ }^{12}$ Boom, "A History of Animal Welfare Science," 124.

${ }^{13}$ Kirk, "The Invention of the 'Stressed Animal"”.

14 "Ethology: Claims and Limits of a lost Discipline", Podcast Series Wissenschafts Portal Gerda Henkel Stiftung, https://lisa.gerda-henkel-stiftung.de/ethology_claims_and_limits_ of_a_lost_discipline_podcast_series? nav_id=9149 [15.05.2021].

${ }^{15}$ Burkhardt, Patterns of Behavior, 418-420, 427-434.
} 
TV shows by zoologist Desmond Morris helped popularise the new discipline for mass-audiences. ${ }^{16}$

However, ethology's rising star also unleashed centrifugal forces. Among senior ethologists, a major point of contention centred on whether ethological animal behaviour models could be applied to other contexts. While Tinbergen remained concerned about diluting ethology's authority by overstating findings, Konrad Lorenz extended already outdated hydrological models to humans in his 1963 book On Aggression. According to Lorenz, aggression was an evolutionary force in human history that could trigger catastrophes but could also be controlled by collective releases like Olympic Games. ${ }^{17}$ The book proved controversial. Some senior ethologists like William Thorpe modified Lorenz's claims but defended the underlying notion that ethological explanations of behaviour could drive the future development of social sciences like sociology and psychology. ${ }^{18}$ By contrast, long-standing critics of ethology like UK Chief Scientific Adviser, Solly Zuckerman, used Lorenz's book to attack the discipline for overselling its findings. ${ }^{19}$ In 1967, Oxford zoologist Desmond Morris further destabilised early ethology's focus on animal behaviour. In the Naked Ape, Morris applied ethological approaches to human evolution and sexual selection-including endorsements of being naked and much-criticised claims about alleged female traits and social roles. ${ }^{20}$ Tinbergen disassociated himself from such claims. In his 1968 inaugural lecture as Oxford's Professor of Animal Behaviour, he noted that ethology could help explain human behaviour but that existing claims were "no more than likely guesses." 21

While On Aggression, Naked Ape, and the 1973 Nobel Prize focused public attention on the work of older ethologists, younger researchers were already breaking new ground. In contrast to classic ethology's focus on causation, studies of neurophysiology, sociobiology, and evolutionary

\footnotetext{
${ }^{16}$ Burkhardt., Patterns of Behavior, 440, 444-446; Hans Kruuk, Niko's Nature. The Life of Niko Tinbergen and his Science of Animal Behaviour (Oxford: Oxford University Press, 2003), 221; Morris hosted Zootime between 1956 and 1967.

${ }^{17}$ Konrad Lorenz, Das Sogenannte Böse. Zur Naturgeschichte der Aggression (Wien: Borotha Shoeler, 1963).

${ }^{18}$ W.H. Thorpe, “Zoology and Behavioural Sciences,” Nature 216/5110 (07.10.1967), 20.

${ }^{19}$ Solly Zuckerman, “The Human beast," Nature 212/5062 (05.11.1966), 563-564; see also: "Is Ethology Respectable?," Nature 216/5110 (07.10.1967), 10.

${ }^{20}$ Desmond Morris, The Naked Ape. A Zoologist's Study of the Human Animal (New York: McGraw Hill, 1967).

${ }^{21}$ Quoted according to Burkhardt, Patterns of Behavior, 440.
} 
function became the "rage" 22 in animal behavioural sciences after William Hamilton's path-breaking 1964 publications on kin selection and E.O. Wilson's New Synthesis in 1975. Rather than querying behavioural motivation at the level of the individual, younger researchers used quantitative socio-biological approaches to study how traits and 'selfish genes' structured behaviour at the group level. Others focused on the adaptive dimensions of animal behaviour in an ecological context or on behaviour's cognitive and affective dimensions. ${ }^{23}$

For an increasing number of researchers in this latter group, animal welfare offered a comparatively well-funded niche to expand into and satisfy growing calls for ethology to become more 'applied.' 24 Their growing involvement with farm animal welfare brought applied ethologists into contact and conflict with veterinary researchers prioritising physiological measurements of stress. Writing to Nature in 1969, William Thorpe had already criticised the fact that the government's FAWAC “included no member capable of expressing authoritatively the current views and results of scientists working on animal behaviour." 25 The dominance of nonethological voices on FAWAC had led to a disregard of Brambell recommendations and a narrow equation of welfare with the absence of pain. Their lack of engagement with affective states and behaviour meant that resulting FAWAC codes were "a retrograde step and would, in fact, condone in farming practice operations which would not be tolerated (...) in a scientific or medical laboratory in this country without special license." 26

However, ideas about how exactly ethological approaches could be applied to farm animal welfare varied. Although there was agreement that behaviour mattered, there was no consensus on what a behaviour meant and how it could be correlated with physiological data. ${ }^{27}$ The result was a prolonged phase of what science and technology studies scholars describe

${ }^{22}$ Burkhardt, Patterns of Behavior, 464.

${ }^{23}$ Burkhardt, Patterns of Behavior, 460-465.

${ }^{24}$ Burkhardt, Patterns of Behavior, 458; Robert Kirk, "The Invention of the 'Stressed Animal'," 253-259.

${ }^{25}$ W.H. Thorpe, "Welfare of Domestic Animals," Nature 224/5214 (04.10.1969), 18; for the wider evolution of contemporary notions of stress see Robert Kirk, "The Invention of the 'Stressed Animal'," 241-263.

${ }^{26}$ W.H. Thorpe, "Welfare of Domestic Animals," 20.

${ }^{27}$ David Fraser, Understanding Animal Welfare; Robert Kirk, "The Invention of the 'Stressed Animal',' 253-259. 
as scientific "tinkering" 28 with different groups testing distinct methodological approaches and trialling creative experimental setups.

Some researchers tried to assess whether farm animals' behaviour could be classified as normal or abnormal when compared to a species' 'natural' behaviour in the 'wild.' 29 This approach proved especially popular among veterinary researchers. Despite many veterinarians' focus on stress (see above), ethology was by no means an alien field within the veterinary sciences. Founded in 1966, the Society for Veterinary Ethology-now the International Society for Applied Ethology—was initially open only to veterinarians and drew on two centres of learning in Cambridge and Edinburgh. ${ }^{30}$

In Cambridge, veterinarian Alastair Worden's Institute for the Study of Animal Behaviour (ISAB) had recruited veterinarians to study 'wild' animals since 1944 and began to extend its focus to domestic animals in the late 1950s. ${ }^{31}$ Another centre of veterinary ethology emerged in Edinburgh. In 1959, Scottish veterinarian Andrew Fraser conducted important ethological studies on 'abnormal' behaviour in farm settings. Fraser was subsequently encouraged to promote animal ethology at Edinburgh's Royal (Dick) College of Veterinary Medicine and drew on local support from a group of researchers working at Edinburgh's Poultry Research Centre (now Roslin Institute). ${ }^{32}$

Headed by animal geneticist David Wood-Gush, the Poultry Research Centre group compared animal behaviour in 'natural' and agricultural

\footnotetext{
${ }^{28}$ Karin D. Knorr, "Tinkering toward Success: Prelude to a Theory of Scientific Practice," Theory and Society 8/3 (1979), 347-376; Helen Curry, Evolution Made to Order: Plant Breeding and Technological Innovation in Twentieth-Century America (Chicago: University of Chicago Press, 2016), 9; Dmitriy Myelnikov, "Tinkering with genes and embryos: the multiple invention of transgenic mice c. 1980," History and Technology 35/4 (2019), 425-452.

${ }^{29}$ [Stamp] Dawkins, Animal Suffering, 39-40; 110-111.

${ }^{30}$ Andrew Fraser, "A Short Biography of Andrew Fraser, written by him in March 2008," Applied Ethology, https://www.applied-ethology.org/res/dr_\%20andrew\%20fraser_\%20 isae\%20honorary\%20fellow.pdf [11.03.2020].

${ }^{31}$ J.C. Petherick and Ian J.H. Duncan, “The International Society for Applied Ethology: going strong 50 years on," in Jennifer Brown, Yolande Seddon and Michael Appleby (eds.), Animals and Us -50 years and more of applied ethology (Wageningen: Wageningen Academic Publishers, 2016), 30-31.

${ }^{32}$ Andrew Fraser, "Displacement activities in domestic animals," British Veterinary Journal Vol. 115 (1959), 195-200; David Fraser, Understanding Animal Welfare. The Science in its Cultural Context (Oxford: UFAW, 2008), 125; Petherick and Duncan, "The International Society for Applied Ethology," 30.
} 
settings. ${ }^{33}$ In an influential 1973 review, Wood-Gush challenged the Brambell Report's equation of welfare with the freedom to express 'natural' behaviour. It was possible to breed birds for better adaptation to battery cages, cage designs did not necessarily frustrate so-called displacement or vacuum behaviours, and not every behavioural frustration was detrimental to welfare. This did not mean that affective states were irrelevant. Comparative research on wild fowls and battery hens indicated that social isolation and lack of stimulus increased the likelihood of feather pecking or cannibalism. However, to be of practical relevance, welfare observations had to be reconciled with economic realities. Conventional farrowing systems' frustration of nest building by sows could be characterised as a welfare problem even as they prevented the crushing of piglets. ${ }^{34}$ Because the avoidance of all behavioural frustration on farms was "impossible," 35 researchers should focus on understanding which frustration was tolerable and which was damaging. Wood-Gush's group subsequently began to experiment with the rewilding of farm animals and alternative rearing systems. This included releasing intensively farmed pigs into the semi-wild environment of the Edinburgh Pig Park and using results to design a new family pen housing system for farms. ${ }^{36}$

While Wood-Gush employed a comparative approach to define 'normal behaviour' and welfare, other researchers focused on evolutionary adaptiveness to reconcile ethology with existing notions of thrift. Having trained under Thorpe before becoming the first person to hold a chair in animal welfare in 1986, Reading- and Cambridge-based biologist Donald $\mathrm{M}$. Broom proposed that welfare be used only to refer to an animal's state and not to external benefits given to it. According to Broom, welfare could be assessed on a scale running from good to bad and was directly related to an animal's ability to cope with its immediate environment. Coping could be measured via classic physiological indicators like survival

${ }^{33}$ Newberry and Sandilands, "Pioneers of applied ethology," 57-58.

${ }^{34}$ D.G.M. Wood-Gush, "Animal Welfare in Modern Agriculture," British Veterinary Journal 129 (1973), 167-173.

${ }^{35}$ D.G.M. Wood-Gush, "Animal Welfare in Modern Agriculture," British Veterinary Journal 129 (1973), 173.

${ }^{36}$ Alex Stolba \& D.G.M. Wood-Gush, "The identification of behavioural key features and their incorporation into a housing design for pigs," Annal Recher Vét 15 (1984), 287-298; Victoria Sandilands, "David Wood-Gush The Biography of an Ethology Mentor," Applied Animal Behaviour Science 87 (2004), 173-176; David Fraser, Understanding Animal Welfare, 169-176. 
into old age and the ability to produce offspring. Stress in this context remained a negative concept, which overtaxed an individual's control systems and reduced fitness. Affective states were important but were only one component contributing to an animal's welfare. ${ }^{37}$

For other researchers, understanding what animals wanted was key to defining welfare. While Wood-Gush and Broom did not deny that affective states were important, they were not particularly interested in using them as a door through which to comprehend an animal's point of view. Establishing this point of view became the focus of an influential third group of mostly ethology-trained researchers. Since the 1960s, an increasing amount of research on animal consciousness, such as preference indication by rats and mirror self-awareness among chimpanzees, had overthrown many earlier taboos about studying animals' mental states. ${ }^{38}$ In 1976, US ethologist Donald Griffin's influential The Question of Animal Awareness expanded earlier claims by researchers like William Thorpe and argued that non-humans had consciousness: "it even seems likely that we can anticipate the eventual emergence of a truly experimental science dealing with the mental experiences of other species." 39

In Oxford, Tinbergen student Marian Stamp Dawkins built on Griffin's work to propose a new preference-oriented approach to welfare. Dawkins cautioned against defining welfare solely in terms of stress and (ab)normal behaviour or by trying to understand animal preferences via intuition. ${ }^{40}$ Instead, she designed experiments that queried animals' preferences and how they adapted to different environments. ${ }^{41}$ In 1977, she tested whether hens preferred battery or larger pens. To her surprise, the animals spent equal amounts of time in both settings. ${ }^{42}$ Responding to criticism that this

\footnotetext{
${ }^{37}$ Broom, "A History of Animal Welfare Science," 128-133; Fraser, Understanding Animal Welfare, 72-73.

${ }^{38}$ [Stamp] Dawkins, Animal Suffering, 16-26; Katja Guenther, "Monkeys, Mirrors, and Me: Gordon Gallup and the Study of Self-Recognition," Journal of the History of the Behavioural Sciences 53/1 (2017), 5-27.

${ }^{39}$ Donald Griffin, The Question of Animal Awareness. Evolutionary Continuity of Mental Experience (New York: Rockefeller University Press, 1976), 14.

${ }^{40}$ [Stamp] Dawkins, Animal Suffering, 1-54; Marian Stamp Dawkins, "From an animal's point of view: Motivation, fitness, and animal welfare," Behavioural and Brain Sciences 13 (1990), 1-3.

${ }^{41}$ [Stamp] Dawkins, Animal Suffering, 110-116.

${ }^{42}$ Marian [Stamp] Dawkins, "Do hens suffer in battery cages? Environmental preferences and welfare," Animal Behaviour 25 (1977), 1034-1046; Fraser, Understanding Animal Welfare, 191-193.
} 
result might merely show what animals were accustomed to, ${ }^{43}$ she next fused (neo-)liberal economic and ethological theories by designing choice experiments in which animals worked towards certain goals. The harder an animal was willing to work for something, the more important this factor seemed to be for its welfare. Results were then calibrated against work performed to achieve commonly agreed-on welfare components like food. The 'price' an animal was willing to pay for different factors could be traded and compared. 'Price elasticity' could be measured by varying required workloads and demand could be assessed by minimising 'income' in the form of limiting time to access a resource. ${ }^{44}$

For Dawkins and other members of the 'feelings school,' including Wood-Gush student Ian Duncan, welfare definitions had to encompass an animal's mental and physical health, harmony with its environment or the ability to adapt without suffering to a new artificial environment, and a consideration of an animal's feelings and preferences. Suffering was not just constituted by pain and stress but by a wide range of unpleasant emotional states including subjective feelings like boredom. ${ }^{45}$

Set out in her influential 1980 book Animal Suffering: The Science of Animal Welfare, ${ }^{46}$ Dawkins' preference-centred research approach bore an uncanny resemblance to contemporary economic and political theories emphasising individual needs and desires. ${ }^{47} \mathrm{It}$ is a long-standing truism in the history of science that science is always also a reflection of the society in which it is conducted. This is particularly true for animal welfare science. As described by animal scientist David Fraser, its focus on providing scientific parameters for inherently normative concepts meant that animal welfare research was both "science-based" and "values-based." 48

${ }^{43}$ Ian J. H. Duncan, "The interpretation of preference tests in animal behaviour," Applied Animal Ethology 4 (1978), 197-200.

${ }^{44}$ [Stamp] Dawkins, Animal Suffering, 83-97; Fraser, Understanding Animal Welfare, $73,197-203$.

${ }^{45}$ Ian J.H. Duncan and Marian Stamp Dawkins, "The problem of assessing 'well-being' and 'suffering' in farm animals," in D. Smidt et al. (eds.) Indicators relevant to farm animal welfare (The Hague: Martinus Nijhoff, 1983), 13-24.

${ }^{46}$ [Stamp] Dawkins, Animal Suffering.

${ }^{47}$ In 1990, Dawkins contextualised her application of economic theory by noting that other biological fields and psychologists had also adopted economics of choice to explain population dynamics and behaviour; Stamp Dawkins, "From an animal's point of view," 4-5.

${ }^{48}$ Fraser, Understanding Animal Welfare, 273. 
In laboratories, in official circles, and on farms, researchers constantly triangulated between three different needs: the need to design experimental systems that generated 'objective' and reproducible welfare data, the need to propose parameters that were meaningful to the producers and politicians who would have to adopt them, and the need to align research programmes with wider societal notions of welfare. Emerging metrics and standards thus not only reflected researchers' individual methodologies but also represented an often-unstable compromise between what different academic disciplines, non-academic sponsors, agricultural producers, and consumers valued most.

No part of this hybrid research and standard-setting process was easy. There was a basic consensus that welfare could be measured. There was also an increasing amount of disciplinary coordination with the already mentioned Society for Veterinary Ethology gaining more members and launching a dedicated journal (Applied Animal Ethology, now Applied Animal Behaviour Science) in 1974. ${ }^{49}$ However, despite many methodological overlaps ${ }^{50}$ the three academic schools of fitness, affective states, and 'natural' rearing continued to disagree on the relative weighting and usefulness of different welfare indicators. ${ }^{51}$

\section{Combative Science: Welfare Research in a Time of Counter Science}

All the while, pressure to apply welfare research was increasing. With more British animals being produced by fewer workers, ${ }^{52}$ scientists were asked to evaluate existing systems and to define welfare standards for the design of new intensive and non-intensive systems. For researchers, this was both a chance and a challenge. In 1972, British government policy shifted from supporting comparatively independent research councils that sponsored 'basic research' towards supporting government departments that sponsored 'applied research.' As described by Dmitriy Myelnikov, this shift was

\footnotetext{
${ }^{49}$ Suzanne Millman, Ian Duncan, Markus Stauffacher, and Joseph Stookey, “The impact of applied ethologists and the International Society for Applied Ethology in improving animal welfare," Applied Animal Behaviour Science, 86 (2004), 299-311; Andrew Fraser, "A Short Biography of Andrew Fraser".

${ }^{50}$ Broom, "A History of Animal Welfare Science," 127.

${ }^{51}$ Fraser, Understanding Animal Welfare, 83, 230-232.

${ }^{52}$ Yago Zayed, "Agriculture: historical statistics," House of Commons Library Briefing Paper 03339 (2016), 7-10.
} 
particularly pronounced with regard to the Agricultural Research Council, which saw about half of its budget moved to MAFF. ${ }^{53}$ Their focus on applied research meant that welfare researchers stood to profit from this development. Enterprising behavioural researchers could also tap into a growing number of non-governmental funding streams-something that would become increasingly important in the uncertain 1980s funding environment for universities (Chap. 12). ${ }^{54}$

The increase of funding sources required shrewd diplomacy on the part of scientists. ${ }^{55}$ To maintain their public standing as trustworthy experts, welfare researchers had to not only minimise internal disagreements on methodologies but also find ways of managing funder expectations without compromising research integrity. Appearing 'objective' and resisting pressure to produce favourable results was particularly important during a time of widespread polarisation over what constituted acceptable welfare and whose expertise to trust. Similar to parallel controversies about environmental expertise, the 1970s saw formerly 'backstage' decision-making about animal welfare give way to increasingly antagonistic 'frontstage' public clashes between officials, producers, and activists over whose version of welfare to trust (Chap. 8). ${ }^{56}$ As records from Ruth Harrison's FACT and the RSPCA show, being able to commission one's own (counter) science and mobilise experts in committees, parliament, and public became key campaigning assets - albeit ones that caused problems with more radical campaigners, who opposed all forms of animal experimentation. ${ }^{57}$

In the case of the RSPCA, the 1970s saw the Society tread new ground by actively courting animal welfare researchers (Chap. 9). Significantly, the Society's historical opposition to 'cruel' animal experimentation made it focus on commissioning behavioural rather than physiological research. The RSPCA's 1969 general meeting had passed a resolution originally

${ }^{53}$ Dmitriy Myelnikov, "Cuts and the cutting edge: British science funding and the making of animal biotechnology in 1980s Edinburgh," The British Journal for the History of Science 50/4 (2017), 708-709; boundaries between both categories of science were ideal type and blurred, there was also no pronounced antagonism between the ARC and MAFF.

${ }^{54}$ Jon Agar, Science Policy Under Thatcher (London: UCL Press, 2019), 21-22, 73-86, $263-265$.

${ }^{55}$ For developments in the US see: Agricultural Research: Background and Issues (Washington DC: Congressional Research Service, 2020), 12-14.

${ }^{56}$ Matthias Heymann, "1970s: Turn of an Era in the History of Science?, Centaurus 59.1-2 (2017), 1-9; Hilton et al., Politics of Expertise, 14-15; Cassidy, Vermin, 48-49, for front- and backstage dimensions of policy see 205.

${ }^{57}$ Harrison and the RSPCA were not unique in bringing "expertise to expertise", Hilton et al. Politics of Expertise, 81-82. 
tabled by Ruth Harrison according to which the Society should spend "more of its resources and influence on the welfare of farm animals." 58 The Society's leadership had responded by hiring an additional veterinary officer in 1970 to give welfare advice and by remodelling its existing farming committee along "rather different lines": "The new committee would be composed essentially of certain Council members of the RSPCA, together with some acknowledged experts in the veterinary, farming and ethological fields from outside the Council of the RSPCA."59

After a "considerable search," 60 a number of renowned experts agreed to help. At its first meeting on June 7, 1971, the RSPCA's new Farm Livestock Advisory Committee (FLAC) consisted of a zoologist, an ethologist, veterinarians, full-time farmers, a representative of the British Horse Society, and a lawyer specialising in animal jurisprudence. ${ }^{61}$ Maintaining their scientific independence was very important to FLAC experts. According to University of London primatologist and FLAC chairman John R. Napier, FLAC "was an independent committee and to have any credibility in the eyes of the general public, it must be seen to be objective and uninfluenced." 62 In contrast to some RSPCA activists, FLAC was not opposed to intensive farming per se. Its mission was rather "to define what was reasonable in animal welfare terms" ${ }^{\prime 3}$ and press for regulatory improvements. According to Napier, "we had, as a society, undoubtedly to accept that domestication was inevitable, but the degree to which this was taken must be closely watched. We had to draw the line between comfort and

${ }^{58}$ RSPCA Archives, IF/25/1 RSPCA Intensive Farming 2 of 2, The RSPCA and Farm Livestock. Report No. V. 11 produced by the Veterinary Department of the RSPCA for the Panel of Enquiry. February 1974, 5.

${ }^{59}$ RSPCA Archives, IF/25/1 RSPCA Intensive Farming 2 of 2, The RSPCA and Farm Livestock. Report No. V. 11 produced by the Veterinary Department of the RSPCA for the Panel of Enquiry. February 1974, 5.

${ }^{60}$ RSPCA Archives, IF/25/1 RSPCA Intensive Farming 2 of 2, The RSPCA and Farm Livestock. Report No. V. 11 produced by the Veterinary Department of the RSPCA for the Panel of Enquiry. February 1974, 6.

${ }^{61}$ Anon, "Society for Veterinary Ethology, 'Stress in Farm Animals' - proceedings of joint symposium with the Royal Society for the Prevention of Cruelty to Animals, London 25-26, May 1973," British Veterinary Journal 130 (1974), 85; the Society's veterinary department under Chief Veterinary Officer Philip Brown was closely affiliated with FLAC.

${ }^{62}$ RSPCA Archives, Minutes FLAC, Meeting, 12.10.1971, 3.

${ }^{63}$ RSPCA Archives, IF/25/1 RSPCA Intensive Farming 2 of 2, The RSPCA and Farm Livestock. Report No. V. 11 produced by the Veterinary Department of the RSPCA for the Panel of Enquiry. February 1974, 7. 
discomfort and cruelty, and time and again we were brought back to the conclusion that the animals' behaviour may be our best barometer." ${ }^{\prime \prime}$

FLAC's first job was to advise the RSPCA with regard to the revised 1971 draft animal welfare codes (Chap. 8). Although it commended new veterinary rights of entry, it noted that MAFF's State Veterinary Service was understaffed and not carrying out welfare inspections. FLAC was even more critical of FAWAC, which had failed "to reform and educate in animal welfare. No significant research had been sponsored, nor the right questions asked, nor the relevant new information publicised." ${ }^{65}$ In the case of welfare codes for veal husbandry, FLAC pushed for systems that provided sufficient space for calves to groom themselves, optimum rather than minimum dietary iron levels, and roughage to aid rumen development. It was hoped that consumer information would prevent intensive veal systems from further spreading in the UK. ${ }^{66}$

Between 1972 and 1976, the number of items on FLAC's agenda grew rapidly. Responding to requests by the RSPCA Council, MAFF, and members of the public, the committee reviewed the non-stun slaughter of animals, early fowl weaning, the introduction of new battery rearing systems for piglets, a 'protecta' farrowing system to protect piglets from being crushed by sows, castration, the docking of pigs' tails, and live animal exports. ${ }^{67}$

Rather than consulting experts on an ad hoc basis, FLAC also pushed for long-term RSPCA sponsorship of the new "sub-discipline of farm livestock ethology." ${ }^{68}$ In October 1971, FLAC chairman John Napier noted that FLAC should:

be forward looking and that it would require ethological evidence if it were to make valid recommendations. Very little work had to date been done on

${ }^{64}$ RSPCA Archives, Minutes FLAC, Meeting, 09.02.1972, 2.

${ }^{65}$ RSPCA Archives, IF?25/1 RSPCA Intensive Farming 2 of 2, The RSPCA and Farm Livestock. Report No. V. 11 produced by the Veterinary Department of the RSPCA for the Panel of Enquiry. February 1974, 5.

${ }^{66}$ RSPCA Archives, Minutes FLAC, Meeting, 20.07.1971, 3; Meeting, 12.10.1971, 2-3.

${ }^{67}$ RSPCA Archives, Minutes FLAC, Meeting, 09.02.1972, 1-2; Meeting, 24.04.1972, 2-3, 4-5; Meeting, 27.02.1973, 1-2; Meeting, 14.05.1973, 3; Meeting, 04.12.1973, 2; Meeting, 09.09.1975, 2, 4; Meeting, 27.04.1976, 4; Meeting, 01.09.1976, 2-3; RSPCA Archives, Minutes FLAC, Report on Intensive Farming Produced for RSPCA Council by the Veterinary Department, 1-2.

${ }^{68}$ Anon, "Society for Veterinary Ethology, 'Stress in Farm Animals' - proceedings of joint symposium," 85 . 
animal behaviour under intensive farming conditions. We needed more information, and one way of obtaining it would be to sponsor certain selected lines of work in the ethological field. ${ }^{69}$

According to Napier, producing "ethograms" or "repertoires of the nature and context of every classifiable action, fixed motor patterns, performed by farm animals" 70 was more than a disinterested scientific endeavour. It would help the Society "interpret the meaning of 'unnecessary suffering', the key phrase in the 1911 Protection of Animals Act and all subsequent legislation"71 and aid the development of regulations for abnormal stress. Although RSPCA Vice-Chairman Frank Burden insisted that "we did not need scientific evidence that certain practices were cruel, or wrong, we knew they were," ${ }^{72}$ Napier's initiative was supported by other FLAC members. According to veterinary ethologist Andrew Fraser, sponsoring research would be an "excellent public relations exercise": "there were large areas where descriptive observations would be of much value to [FLAC]." "73 Quoting Liverpool animal researcher Roger Ewbank, Fraser claimed that "one of the first signs (and possibly the only sign) of stress/ distress/ deprivation of intensively kept farm animals may be the development of abnormal behaviour patterns." ${ }^{\prime 4}$ The attending BVA president Nigel Snodgrass agreed that "this information was desperately needed."75 Following extensive debate, FLAC decided to call for welfare research scholarships, which would not cost much and "ensure that the reins were firmly"76 in the RSPCA's hands.

RSPCA sponsorship of behavioural research was approved by the Society's Council in early 1972 on the condition that research would be observational and "non-experimental." ${ }^{77}$ This limitation to

\footnotetext{
${ }^{69}$ RSPCA Archives, Minutes FLAC, Meeting, 12.10.1971, 4.

${ }^{70}$ Anon, "Society for Veterinary Ethology, 'Stress in Farm Animals' - proceedings of joint symposium," 85.

${ }^{71}$ Anon, "Society for Veterinary Ethology, 'Stress in Farm Animals' - proceedings of joint symposium," 85.

${ }^{72}$ RSPCA Archives, Minutes FLAC, Meeting, 12.10.1971, 4.

${ }^{73}$ RSPCA Archives, Minutes FLAC, Meeting, 12.10.1971, 4; Fraser resigned from FLAC due to other commitments in 1974; RSPCA Archives, Minutes FLAC, Meeting, 25.06.1974, 1 .

${ }^{74}$ RSPCA Archives, Minutes FLAC, Meeting, 09.02.1972, 3.

${ }^{75}$ RSPCA Archives, Minutes FLAC, Meeting, 09.02.1972, 3.

${ }^{76}$ RSPCA Archives, Minutes FLAC, Meeting, 09.02.1972, 3.

${ }^{77}$ RSPCA Archives, Minutes FLAC, Meeting, 24.04.1972, 2.
} 
non-experimental research had important consequences: it effectively excluded research on physiological indicators of abnormal stress and pain from RSPCA sponsorship and simultaneously generated important pumppriming funds for the budding community of applied ethologists. ${ }^{78}$

The first project financed by FLAC was a comprehensive survey of behavioural welfare research in the UK. Between July and November 1972, one of Napier's graduate students, Peter Lattin, ${ }^{79}$ visited 21 academic institutions and 50 researchers across the UK. In his report, Lattin noted that while many people were interested in behavioural work, "one very often felt it was a political and economic interest." 80 To avoid sponsoring biased research, FLAC should fund theoretical work by trained ethologists in zoology departments and field work in agricultural and veterinary colleges. ${ }^{81}$ Only very few research centres had the capacity to serve as bases for useful applied research.

Building on Lattin's report, FLAC awarded the first RSPCA Farm Animal Behaviour Awards in May 1973. The two groups chosen were based at the University of Sussex and the Edinburgh School of Agriculture. ${ }^{82}$ At Sussex, Dr Marthe Kiley and Prof Richard Andrew received $£ 2000$ to conduct behavioural research on calves and mother/calf relationships between birth and weaning in intensive and extensive veal units. ${ }^{83}$ In Edinburgh, David Wood-Gush's group used RSPCA sponsorship to study the excretory behaviour of pigs in extensive systems to better understand behavioural problems in farrowing crates and sow stalls. RSPCA funding was later also used to study the effects of providing bedding material during farrowing and to co-finance Edinburgh's semi-wild herd of intensively bred pigs. ${ }^{84}$

\footnotetext{
${ }^{78}$ Anon., "Society for Veterinary Ethology, 'Stress in Farm Animals' - proceedings of joint symposium," 86.

${ }^{79}$ RSPCA Archives, Minutes FLAC, Meeting, 18.09.1972, 1.

${ }^{80}$ RSPCA Archives, Minutes FLAC, Meeting, 14.11.1972, 2.

${ }^{81}$ Anon., "Society for Veterinary Ethology, 'Stress in Farm Animals' - proceedings of joint symposium," 86.

${ }^{82}$ RSPCA Archives, Minutes FLAC, Meeting, 14.05.1973, 2.

${ }^{83}$ RSPCA Archives, Minutes FLAC, Meeting, 25.06.1974, 5; RSPCA Archives, IL/24/5 RSPCA Intensive Farming 1 of 2, RSPCA Grant Annual Report 1973/1974 RJ Andrew and M. Kiley; RSPCA Archives, IF/25/1 RSPCA Intensive Farming 2 of 2, The RSPCA and Farm Livestock. Report No. V. 11 produced by the Veterinary Department of the RSPCA for the Panel of Enquiry. February 1974, 9.

${ }^{84}$ RSPCA Archives, Minutes FLAC; Meeting, 23.11.1978, 4; Meeting, 01.05.1979, 2; RSPCA Archives, IL/24/5 RSPCA Intensive Farming 1 of 2, John Napier, Farm Animal
} 
FLAC lobbying also led to RSPCA conference sponsorship. In May 1973, the RSPCA co-organised the Society for Veterinary Ethology's 1973 symposium on Stress in Farm Animals at the London Zoo. ${ }^{85}$ This was the first ever "purely scientific" 86 meeting organised by the Society since its foundation in 1824 . Covered by the New Scientist, ${ }^{87}$ conference proceedings were dominated by physiological research on stress but also featured important behavioural contributions by Andrew Fraser, Roger Ewbank, and Ian Duncan. ${ }^{88}$ During the opening ceremony, John Napier praised RSPCA chairman John Hobhouse's decision to move the RSPCA "towards a more scientifically oriented approach to the problems of animal welfare." ${ }^{89}$ FLAC grants would hopefully help animal behaviour become a "meeting ground for psychologists, zoologists, physiologists, anatomists, geneticists, ecologists, and many others." 90

Napier's vision for FLAC sponsorship of interdisciplinary behavioural research was ultimately constrained by the RSPCA Council's limitation of Behaviour Awards to non-experimental research. Where exactly the line between observational and experimental research lay was unclear. Attempts to define it not only exposed differences of opinion between FLAC researchers and their RSPCA sponsors but also highlighted the limits of expert power in the value-laden field of welfare science. Historically, the experiment had functioned as a carefully staged way to produce 'self-evident' truths and trust in the authority of learned experts. ${ }^{91}$ Traditional

Behaviour Awards, 1974-1975; Interim Report Edinburgh University; FLAC later also considered financing limited studies on the economic feasibility of different systems for laying hens, RSPCA Archives, FLAC Minutes, Meeting, 23.11.1978, 1; Inlay: The Proposed Straw Yard Project and Alternative Systems".

${ }^{85}$ RSPCA Archives, Minutes FLAC, Meeting, 18.09.1972, 2.

${ }^{86}$ RSPCA Archives, IF/25/1 RSPCA Intensive Farming 2 of 2, The RSPCA and Farm Livestock, Report No. V. 11 Produced by the Veterinary Department of the RSPCA for the Panel of Enquiry. February 1974, 18.

87 "Domesticated animals breed on regardless," New Scientist, 14.06.1973, 665.

${ }^{88}$ Anon., "Society for Veterinary Ethology, 'Stress in Farm Animals' - proceedings of joint symposium," 85-95.

${ }^{89}$ Anon., "Society for Veterinary Ethology, 'Stress in Farm Animals' - proceedings of joint symposium," 85.

${ }^{90}$ Anon., "Society for Veterinary Ethology, 'Stress in Farm Animals' - proceedings of joint symposium," 86.

${ }^{91}$ A concept most famously set out in Steven Shapin and Simon Schaffer, Leviathan and the air-pump: Hobbes, Boyle, and the experimental life (Princeton: Princeton University Press, [1985] 2011). 
expert authority was, however, inherently limited in mandated sciences like animal welfare science, which simultaneously tackled moral and scientific claims. While older experts like Thorpe and Huxley had developed scientific principles of humane experimentation as a way to re-establish science's progressivist moral role after the Second World War (Chap. 4), younger activists challenged scientists' authority to define ethically acceptable experimentation.

Tensions about what constituted moral research and who was allowed to define it escalated when FLAC decided to sponsor behavioural research at the University of Oxford. After turning down earlier proposals, ${ }^{92}$ FLAC had awarded $£ 2000$ in 1974 to Marian Dawkins to study poultry behaviour. Dawkins wanted to assess animals' welfare preferences by rearing and then splitting a group of egg-laying hens in two. To avoid confirming learnt preferences, one group of birds would become accustomed to an extensive free range system and the other would be held in standard intensive conditions, with two birds sharing a cage of 15 inches width. Intensive birds would then be allocated to the extensive free range system and vice versa and given an option to choose the system they preferred.${ }^{93}$ Although Dawkins' research did not require a Home Office License for animal experimentation and involved no manipulation of animals' bodies, the idea of rearing animals in battery cages led to tensions between scientific and non-scientific members of FLAC and the RSPCA Council. While researchers like Peter Lattin, John Napier, and zoologist Peter Jewell commended Dawkins' research as "the most interesting project that had been put before the Committee," 94 lay members including Ruth Harrison and Richard Ryder condemned it as a "cruel experiment." 95

The conflict about what constituted an 'experiment' drew in the wider RSPCA Council and highlighted underlying tensions about whether one should sponsor animal research to improve welfare or oppose all forms of animal exploitation in principle. Following the resignation of RSPCA Chairman Hobhouse (Chap. 9), a joint meeting between FLAC and the RSPCA's Animal Experimentation Advisory Committee on September 2,

\footnotetext{
${ }^{92}$ RSPCA Archives, Minutes FLAC, Meeting, 25.06.1974, 6.

${ }^{93}$ RSPCA Archives, IL/24/5 RSPCA Intensive Farming 1 of 2, M. Dawkins and D. McFarland, Welfare of Domestic Fowl in Relation to their habitat preferences.

${ }^{94}$ RSPCA Archives, Minutes FLAC, Meeting, 18.03.1975, 3.

${ }^{95}$ RSPCA Archives, IL/24/5 RSPCA Intensive Farming 1 of 2, Letter Major Seager, 12.08.1975.
} 
1975, led to an éclat. At the meeting, Dawkins' research was attacked by Richard Ryder, Labour peer Lord Houghton of Sowerby, and parapsychologist and Doctor Who adviser Christopher "Kit" Pedler, who claimed that the Oxford experiments were unscientific. According to Ryder, the RSPCA was "on terribly dangerous ground here": "We have been giving away money in a rather unbusinesslike way, trusting people with whom we are scarcely acquainted, working in laboratories where only occasional inspections have been made by the Society. (...). Obviously the RSPCA must never inadvertently subsidise cruelty." $" 96$

The RSPCA Council subsequently declined an extension of the behavioural awards. This decision enraged FLAC scientists. Resigning as FLAC chairman seven days after the September éclat, John Napier expressed pride in his committee's achievements. Within four years, FLAC had become recognised "as an important body" of welfare expertise, had published the first RSPCA-commissioned research, was organising its second research conference on mutilation, and had pushed the RSPCA to "take part in the academic side of animal welfare." $"$ According to Napier, "it was wrong to describe [Dawkins'] work as experimentation (...) it was very difficult to interpret ethological studies if one did not have any knowledge of, or sympathy with the subject of ethology." 98 The fact that the proposed research did not require a Home Office license had been confirmed by the Home Office, Dawkins, and Oxford's Head of Animal Behaviour Research. Attending RSPCA Council members disagreed: "the Council had been preoccupied during the last two years and probably not made an adequate study of the documents sent to them by the FLAC. Being now reduced in size the new Council was anxious to do everything possible to repair the damage done to the Society by the events of the preceding two years." $" 99$ From now on, decisions over experiments' acceptability would not be made by welfare scientists but by the Council.

Acknowledging its defeat, FLAC decided to no longer refer to behavioural studies "using the terms 'research' or 'experimentation' as these

\footnotetext{
${ }^{96}$ British Library, Richard Ryder Papers, Ryder Dep. 9846 B1, 4, Richard Ryder to Major R. Seager, Executive Director, RSPCA, 18.09.1975, 2-3.

${ }^{97}$ RSPCA Archives, FLAC Minutes, Meeting, 09.09.1975, 1.

${ }^{98}$ RSPCA Archives, FLAC Minutes, Meeting, 09.09.1975, 4; see also: RSPCA Archives, IL:24:5 RSPCA Intensive Farming 1 of 2, Jon Napier: Farm Animal Behaviour Awards, $1974-1975$.

${ }^{99}$ RSPCA Archives, FLAC Minutes; Meeting, 09.09.1975, 5.
} 
could confuse, and possibly worry, certain members of the Council."100 Although the Council resumed payment of the awards, rewording research briefs failed to solve problems. In November 1975, FLAC formulated detailed terms and conditions and reporting requirements for RSPCA funding. ${ }^{101}$ This triggered further tensions with the Council, which had followed suggestions by Ryder and stipulated unannounced control visits by lay Council members. ${ }^{102}$ Warning that universities would resist such a move ${ }^{103}$ FLAC instead proposed visits by the Society's Chief Veterinary Officer or a nominated Council representative. FLAC's new head Prof. Peter Jewell of London's Royal Holloway College hoped that such a person would ideally be "suitably qualified" with a "perhaps easier understanding of the studies taking place, and less possibility of an emotional or arbitrary attitude." 104 FLAC also pressed for one of its members to be there for any visit. ${ }^{105}$

FLAC eventually got its way on research visits and also managed to secure a time-limited funding extension for Dawkins, who was summoned twice to describe her research. ${ }^{106}$ However, the committee's overall influence within the RSPCA was waning. FLAC recommendations restructured the Society's farm animal welfare policies in $1977^{107}$ and members influenced new European welfare codes. ${ }^{108}$ But scientists' attempts to push for a middle ground between "commercial farming interests" and "over-emotional and misleading" 109 attacks on intensification fell on deaf ears. Both the RSPCA Council and general meetings increasingly condemned intensive farming per se. In the case of live animal exports, FLAC failed to prevent RSPCA calls for a complete ban, as opposed to banning only the export of animals

${ }^{100}$ RSPCA Archives, FLAC Minutes, Meeting, 09.09.1975, 5.

${ }^{101}$ RSPCA Archives, FLAC Minutes, Meeting, 11.11.1975, 3.

${ }^{102}$ British Library, Richard Ryder Papers, Ryder Dep. 9846 B1, 4, Richard Ryder to Major

R. Seager, Executive Director, RSPCA, 18.09.1975, 2.

${ }^{103}$ RSPCA Archives, FLAC Minutes, Meeting, 10.02.1976, 2-3.

${ }^{104}$ RSPCA Archives, FLAC Minutes, Meeting, 27.04.1976, 3

${ }^{105}$ RSPCA Archives, FLAC Minutes, Meeting, 09.03.1977, 4.

${ }^{106}$ RSPCA Archives, FLAC Minutes, Meeting, 19.10.1976, 1; 24.01.1978, 5.

${ }^{107}$ RSPCA Archives, FLAC Minutes, Meeting, 06.09.1977, 3; Report on Intensive Farming Produced for RSPCA Council by the Veterinary Department, 3-11.

${ }^{108}$ RSPCA Archives, FLAC Minutes, Meeting, 20.05.1975, 1; 09.09.1975, 8; 20.07.1976, 3; 01.05.1979, 4 .

${ }^{109}$ RSPCA Archives, FLAC Minutes, Report on Intensive Farming Produced for RSPCA Council by the Veterinary Department, 2-3; see also disagreements with RSPCA leadership and other welfare organisations about condemning intensification during the Animal Welfare Year, RSPCA Archives, FLAC Minutes, Meeting, 12.01.1977, 2. 
destined for slaughter. ${ }^{110}$ There were also tensions about whether FLAC could participate in meetings with the NFU, BVA, and MAFF, or whether this would undermine negotiations on animal exports being carried out by the Council in tandem with other welfare organisations. ${ }^{111}$

Increasingly critical of its independent expert committee, the RSPCA Council refused to support a proposed RSPCA Chair or centre for animal welfare in May 1977. ${ }^{112}$ It also informed FLAC that it would no longer support research on animals in unnatural environments. Referring to Dawkins' work, the Council wanted to make it "quite clear to all concerned that a study of animals in an existing environment was quite in order, but putting animals into a specific environment, which perhaps was not in line with the Society's policies, would not be acceptable." "113 Dismayed FLAC members thought "that it was tragic to have this work stopped just when such excellent results (from the RSPCA's point of view) were beginning to come through." 114 Already struggling to find replacements for the numerous researchers resigning from its ranks, ${ }^{115}$ FLAC issued a unanimous rebuttal to accusations that Dawkins' work constituted "bad science": "we considered the results do show how animals may, themselves, indicate their preferences and degrees of comfort, (...). It is much to the credit of the RSPCA to have promoted this work and we wish to reassert our confidence in the value that behavioural studies have in the advancement of animal welfare." 116 Although a site visit by the new RSPCA Chairman Richard Ryder secured a final limited renewal of Dawkins' grant, ${ }^{117}$ growing distrust between the Council and FLAC led to a dissolution of the unruly committee and its replacement with a new RSPCA Farming Department in 1979. ${ }^{118}$

The RSPCA was not the only non-governmental organisation to actively engage with and sponsor farm animal welfare science during the

\footnotetext{
${ }^{110}$ RSPCA Archives, FLAC Minutes; Meeting, 18.09.1972, 3; Meeting, 19.11.1974, 2; Meeting, 21.01.1975, 2; Meeting, 10.02.1976, 5; Meeting, 06.09.1977, 2.

${ }^{111}$ RSPCA Archives, FLAC Minutes; Meeting, 23.05.1978, 4; Meeting, 29.06.1978, 2; British Library, Richard Ryder Papers, Ryder Dep. 9846 Bl/4, Major R. Seager to Richard Ryder, 05.08.1977, 1; Ryder to R. Corbett, 09.08.1977, 1; Seager to Ryder, 12.08.1977; Ryder to B. MacDonald, 25.10.1977, 1-2.

${ }^{112}$ RSPCA Archives, FLAC Minutes; Meeting, 11.05.1977, 2.

${ }^{113}$ RSPCA Archives, FLAC Minutes; Meeting, 11.05.1977, 4.

${ }^{114}$ RSPCA Archives, FLAC Minutes; Meeting, 24.01.1978, 5.

${ }^{115}$ RSPCA Archives, FLAC Minutes; Meeting, 23.11.1978, 3.

${ }^{116}$ RSPCA Archives, FLAC Minutes; Meeting, 24.01.1978, 6.

${ }^{117}$ RSPCA Archives, FLAC Minutes; Meeting, 29.06.1978, 1-2; Meeting, 28.09.1978, 1.

${ }^{118}$ RSPCA Archives, FLAC Minutes; Meeting, 01.05.1979, 5.
} 
1970s. Other major organisations like the UFAW began to publish reviews and handbooks on farm animal welfare. ${ }^{119}$ Engagement was not limited to large charities. Ruth Harrison also systematically strengthened ties with leading welfare scientists. Her success in doing so was partially due to her involvement in official welfare committees and partially due to the expanded activities of her research trust.

During the early 1970s, the Ruth Harrison Research Trust had developed rather slowly. Trustees met irregularly, and funding decisions were mostly influenced by the ad hoc demands of Ruth Harrison's FAWAC work. ${ }^{120}$ The Trust's income also remained based on feet of clay. In 1970, Ruth Harrison appealed to the Marquis of St Innocent "for financial help in work which I feel to be of utmost importance and urgency in helping the animals." 121 While it seemed "unforgiveable to ask for help as soon as I met you," she would "hate to see [the chance to help food animals] slip by" and mentioned that the Trust would "need some $£ 6,000$ to take work firmly forward." 122 To raise money, Ruth Harrison also considered cowriting a book on farm systems with Cambridge veterinary scientist David Sainsbury, with whom she enjoyed a good relationship outside FAWAC (Chap. 8). ${ }^{123}$ However, no book materialised, and resources remained stretched. Writing to the Whitley Animal Protection Trust in 1971, Harrison stressed that she "desperately" needed "money for general expenses" 124 such as a typewriter, a camera, filing cabinets, and a copying

${ }^{119}$ UFAW, The UFAW Handbook on the Care and Management of Farm Animals (Edinburgh: Churchill Livingston, 1971); UFAW continues to sponsor farm animal behaviour and welfare research-the handbook is now in its 5 th edition.

${ }^{120}$ FACT Files, DB, Trustees Meetings, Ruth Harrison Research Trust, Meeting of Trustees (13.02.1971).

${ }^{121}$ FACT Files, DB, Unmarked Green Ryman Folder, Ruth Harrison to Marquis of St. Innocent (19.05.1970), 1 .

${ }^{122}$ FACT Files, DB, Unmarked Green Ryman Folder, Ruth Harrison to Marquis of St Innocent (19.05.1970), 1; while the Marquis does not seem to have donated any money, he forwarded Harrison's request to 'Woody' [Allen?]; FACT Files, DB, Unmarked Green Ryman Folder, Marquis of St. Innocent to 'Woody' (17.06.1970).

${ }^{123}$ FACT Files, DB, Unmarked Green Ryman Folder, Ruth Harrison to WA Burns (20.09.1971); FACT Files, DB, Dr, Sainsbury, David Sainsbury to Ruth Harrison (30.06.1970); David Sainsbury to Ruth Harrison (08.07.1970); FACT Files, DB, Unmarked Red Ryman Folder Ruth Harrison to David Sainsbury (19.09.1971).

${ }^{124}$ FACT Files, DB, Unmarked Green Ryman Folder, Ruth Harrison to WA Burns (20.09.1971). 
machine. In 1973, the Trust's net assets amounted to $£ 4497$, while its income fluctuated between $£ 712$ (1972) and $£ 959.07$ (1973). ${ }^{125}$

It was only following Harrison's exit from the RSPCA Council in 1975 that her Trust's resources and activities experienced a marked increase. FACT financed Harrison's journeys to meetings of the European Standing Committee on animal welfare and networking trips to conferences and animal behaviourists. ${ }^{126}$ Harrison soon became a fixture in seminars and conferences on animal welfare. She also joined relevant societies like the Society for Veterinary Ethology/International Society for Applied Ethology (SVE/ISAE). ${ }^{127}$ Researcher David Fraser later recalled his first encounter with Harrison at David Wood-Gush's Edinburgh office in the 1970s:

There was room for two visitors to sit and talk, but any third person had to sit on a chair behind a filing cabinet, hidden from half the room Ruth Harrison took great interest in our research on farm animal welfare and on one of her visits she was occupying that chair ... After some time, a colleague $\ldots$ appeared at the door ...

'Ah, I see you've got rid of the good lady,' said the colleague.

'No,' came the voice of Ruth Harrison from behind the filing cabinet, 'I'm still here.' ${ }^{128}$

In addition to building personal ties to leading academics, Harrison also used FACT to fund welfare research. Much of this research was observational and mirrored RSPCA Council guidance for FLAC. From 1977 onwards, FACT provided valuable pump-priming funding for Prof Anthony (John) Webster's evaluation of different veal production systems by supporting doctoral research on the behaviour, performance, and

${ }^{125}$ FACT Files, DB, Ruth Harrison Research Trust Accounts 30.06.1973; Harrison Research Trust Accounts 30.06.1974.

${ }^{126}$ FACT Files, DB, Unmarked Green Ryman Folder, David Wood-Gush to Ruth Harrison [ca. 1980]; FACT Files, DB, Bristol Veal-Correspondence, Ruth Harrison to Christine (26.06.1979); FACT Files, DB, Unmarked Green Ryman Folder, T.I. Hughes to Ruth Harrison (15.02.1985).

${ }^{127}$ Donald M. Broom, "World Impact of ISAE: past and future," in Jennifer Brown, Yolande Seddon and Michael Appleby (eds), Animals and Us - 50 years and more of applied ethology (Wageningen: Wageningen Academic Publishers, 2016), 272.

${ }^{128}$ Fraser, "Ruth Harrison - a Tribute," 17. 
health of veal calves in strawyards and crates. ${ }^{129}$ FACT also financed physiological research on the stunning of poultry. ${ }^{130}$

Harrison was not engaging science purely for science's sake. Never wavering from the central demands of her 1964 book and learning from her experiences within FAWAC, she saw research as key to supporting her campaign for legislative reform. Her determination to produce useful results made her a hard taskmaster. A critical and prolific reader of scientific publications, Ruth Harrison demanded frequent and detailed progress reports on FACT-financed projects and did not shy away from challenging individual aspects of research. ${ }^{131}$ In the case of the Bristol veal studies, this habit caused tensions between Harrison and John Webster. Writing to an acquaintance in 1979, Ruth Harrison complained about Webster's student: “[The student] started work in October last year. ... It was on my last visit to the project that I began to have serious doubts about [the student's] real capability of doing the task." ${ }^{32}$ Criticising the study's research premises, Harrison also complained that the student had not "read all the papers I had given the department at the beginning of the project." 133 Although she had agreed not to interfere with or bias the research, Harrison mused, "It could be that we will have to insist on changing our post-graduate student." 134

Three months later, Ruth Harrison reminded Webster that FACT had invested over $£ 5000$ in his student's project. Although FACT was grateful for slight amendments to the project, "you had actually promised us ... a list of the specific results which would accrue from our continual funding of the project. ...-and frankly, your note did not offer us any assurance that what we were seeking ... will actually be achieved." ${ }^{135}$ Ruth Harrison

${ }^{129}$ The project had initially been rejected by the ARC as "premature"; Webster, "Tribute to an Inspirational Friend," 7-8; FACT Files, MD, FACT Files, FACT Publications \& Publicity Material, Pamphlet FACT, 1; FACT Files, DB, Bristol Veal-Correspondence, FACT, Alternative Systems for Veal Calves. Work in progress or proposed for 1980/1981.

${ }^{130}$ FACT Files, DB, Trustees Meetings, FACT. Report to the Trustees (30.06.1977).

${ }^{131}$ FACT Files, DB, Bristol Veal Correspondence, Ruth Harrison to Professor Webster (18.01.1978).

${ }^{132}$ FACT Files, DB, Bristol Veal-Correspondence, Ruth Harrison to Christine (26.06.1979); despite Harrison's initial doubts, the student went on to have a successful research career and relations between Harrison and the student soon improved; FACT Files, DB, Unmarked Green Ryman Folder, Student to Ruth Harrison (03.01.1989).

${ }^{133}$ FACT Files, DB, Bristol Veal-Correspondence, Ruth Harrison to Christine (26.06.1979).

${ }^{134}$ FACT Files, DB, Bristol Veal—Correspondence, Ruth Harrison to Christine (26.06.1979).

${ }^{135}$ FACT Files, DB, Bristol Veal—Correspondence, Harrison to Webster (24.09.1979), 1. 
then listed a number of 'facts' she would like to see confirmed and stressed the need for "positive results at the end of the project." ${ }^{36}$ Repeating her complaints about Webster's PhD student, Harrison ended by demanding research documentation personally signed by Webster: "You know that we are keen to continue financing this work, but only if it is going to be productive." 137

Webster's reply was swift and brusque:

I realise that $£ 6,000$ is a substantial sum for [FACT] and I am very grateful for it. However, you and your sponsors must realise that it constitutes only two year's salary. ..., and no new graduate, however brilliant and energetic, is going to (a) solve the problems of rearing veal calves in straw yards, and (b) sell the idea to the industry on their own in two years. ${ }^{138}$

According to Webster, FACT was contributing about 4 per cent of costs to the mainly MAFF- and research council-funded research. Meanwhile, ca. 30-40 per cent of the project's outcomes directly addressed FACT concerns: "Expressed crudely, one might say that it is money well spent." 139 It was also wrong to demand too much of a PhD student, who was only one year into the project: "If [the student] is to attempt too much, in an effort to offer most of the glory to FACT, [the student] will fail because there is too much for one person to do, ... [and] also fail to set up a proper platform for the next stage of the work." 140

At present, everything was going well, and the student was capable of effective animal observation: "Whether this leads [the student] to conclude what you or I may wish [the student] to conclude is impossible to tell until the observations have been analysed correctly." ${ }^{141}$ Webster also saw "no point in submitting yet another statement of what is going on

${ }^{136}$ FACT Files, DB; Bristol Veal-Correspondence, Harrison to Webster (24.09.1979), 2.

${ }^{137}$ FACT Files, DB; Bristol Veal-Correspondence, Harrison to Webster (24.09.1979), 3.

${ }^{138}$ FACT Files, DB, Bristol Veal-Correspondence, Webster to Ruth Harrison (15.10.1979), 1.

${ }^{139}$ FACT Files, DB, Bristol Veal-Correspondence, Webster to Ruth Harrison (15.10.1979), 1.

${ }^{140}$ FACT Files, DB, Bristol Veal-Correspondence, Webster to Ruth Harrison (15.10.1979), 1 .

${ }^{141}$ FACT Files, DB, Bristol Veal-Correspondence, Webster to Ruth Harrison (15.10.1979), 2 . 
because the project is now clearly defined and you have the details." 142 Following further demands from Harrison, Webster drew a firm line:

Surely it is only fair to use your words, that when a Trust agrees to fund a research programme intended to lead to a $\mathrm{PhD}$, that body should at least allow the graduate student and ... academic supervisor to direct the work over the normal period of three years in the way that best fits the scientific questions. ... I am very grateful to FACT for their support which was particularly welcome as it came at an early stage of development ... However, I cannot and will not allow FACT to dictate the research that goes on in my department. ${ }^{143}$

While the Bristol veal project was successfully concluded with continued FACT support, Harrison's conflicts with Webster reveal the difficulties scientists faced in managing funder expectations, as well as the increasing importance of generating targeted welfare data for campaigners like Harrison.

In FAWAC, Harrison urgently needed Webster's data to counter industry research and break a regulatory deadlock over low-level iron feeds. In 1976, FAWAC's research sub-committee had reviewed iron-deficient feeds in intensive veal husbandry. Citing Animal Machines, the subcommittee had initially recommended a new minimum iron level in calf feeds of $9 \mathrm{~g} / 100 \mathrm{ml}$, and the main FAWAC had compromised on a minimum level of $50 \mathrm{mg} / \mathrm{kg}$ in June 1976. ${ }^{144}$ However, in 1977, the research sub-committee was forced to revise its opinion after new industry data showed no evidence that anaemia was a general problem of intensive veal husbandry. ${ }^{145}$ Because advice on minimum iron levels "was not soundly based in scientific findings," 146 the sub-committee concluded that it could not be passed on to Ministers.

${ }^{142}$ FACT Files, DB, Bristol Veal-Correspondence, Webster to Ruth Harrison (15.10.1979), 2 .

${ }^{143}$ FACT Files, DB, Bristol Veal-Correspondence, Andrew Webster to Ruth Harrison (30.09.1980); Webster himself gives a positive account of his collaboration with FACT; Webster, "Ruth Harrison - Tribute to an Inspirational Friend," 7-8.

${ }^{144}$ TNA MAF 369/217 FAWAC, Minutes of 15th Meeting (22.06.1976), 4-5.

${ }^{145}$ TNA MAF 369/217 Iron in Calf Diets. Report by the Research Sub-committee on an appraisal of the scientific basis for the draft Advice to Ministers (AWC/76/26, enclosed in: A. Foreman to FAWAC (06.05.1977), 1-2.

${ }^{146}$ TNA MAF 369/217 FAWAC, Minutes of 16th Meeting (18.05.1977), 11. 
Harrison was convinced of the opposite but could no longer base her campaigning on the often-anecdotal evidence and synthesist moral argumentation that had characterised her own book and much of Edwardian and early post-war activism. In the combative context of 1970s' expert politics, she needed data and scientific support to counter industry-friendly codes. In FAWAC, she therefore sought to undermine Meat Research Institute data on haemoglobin levels in calves. This led to prolonged clashes with senior FAWAC physiologists over feeds' actual iron content, the validity of industry studies, and whether anaemia could cause suffering in calves. ${ }^{147}$ Unable to generate a FAWAC majority, Harrison resorted to the already familiar tactic of blocking a 'bad' compromise until new data being produced by Webster and others supported her position. In May 1977, David Sainsbury complained to FAWAC chair Prof. Harrison about Ruth Harrison's behaviour at a recent meeting of the General Purposes Sub-committee:

The position is that as a Subcommittee we had agreed all the proposals when we last met ... In fact I was faced, as you know, with a substantial number of proposals almost entirely from Mrs. Harrison, some of a fundamental nature, which were placed in front of me at the meeting and most of which strangely she had not chosen to even mention at previous G.P. Sub-committee meetings. ... I am afraid Mrs. Harrison's tactics promise to delay progress by means which I consider rather dubious. ${ }^{148}$

Others also complained about pre-arranged bullying tactics by Harrison and her supporters, which undermined FAWAC members' ability to present evidence without being "condemned by 'debating points' and in some cases by sheer slander." ${ }^{49}$ Harrison's mixed tactics of political and scientific campaigning nonetheless proved successful. In February 1979, FAWAC's General Purposes Sub-Committee published a list of expected data, which would inform the still-undecided calf code revisions. The list included the FACT-sponsored Bristol calf experiment, whose results would eventually change UK and European legislation. ${ }^{150}$

${ }^{147}$ TNA MAF 369/217 FAWAC, Minutes of 16th Meeting (18.05.1977), 12.

${ }^{148}$ TNA MAF 369/222 DWB Sainsbury to Professor RJ Harrison (24.05.1977); FAWAC, General Purposes Sub-Committee, Extracts from Minutes of 7th Meeting (19.04.1977).

${ }^{149}$ TNA MAF 369/222 FR Bell to RJ Harrison (20.05.1977).

${ }^{150}$ TNA MAF 369/240 FAWAC 18th Meeting (08.02.1979), 1-2; Webster, "Ruth Harrison-Tribute to an inspirational friend," 8. 
By this time, MAFF was facing significant pressure to address FAWAC's poor welfare record. ${ }^{151}$ Divisions within the committee meant that little progress had been made since the Agriculture (Miscellaneous Provisions) Act of 1968. In the case of turkeys, FAWAC had failed to produce new codes despite eight years of review. ${ }^{152}$ MAFF's attempt to create an industry-friendly clearing house for welfare codes had clearly failed (Chap. 8 ). Powerless, unpopular, and divided, FAWAC was replaced with a reformatted Farm Animal Welfare Council (FAWC) in 1979..$^{153}$

The end of FAWAC and the RSPCA's parallel dissolution of FLAC made 1979 a turning point for British farm animal welfare. Beginning in the 1960s and gathering power in the 1970s, centrifugal forces had dissolved established welfare decision-making structures. No part of Britain's animal welfare scene remained untouched: set up as a corporatist committee, MAFF's FAWAC failed to produce viable compromises between increasingly polarised welfarist and industry positions. The failure of corporatist politics was mirrored in the world of welfare campaigning. In the case of the RSPCA, demands for grassroots democracy and conflicts about elite hunting pastimes coincided with the Society's transformation from a conservative charity into a combative and professional NGO with sophisticated in-house scientific expertise. Reaching the height of their influence around 1977, Reform Group members not only remodelled RSPCA leadership and management but also triggered systemic debates about animal rights and the morality of animal exploitation.

Resulting conflicts about what constituted legitimate research and whether scientists alone could define it were indicative of the challenges faced by the new "mandated" 154 discipline of animal welfare science. Tasked with providing objective evidence for normative claims, welfare researchers profited from increased funding but faced pressure to produce useful results. Different sponsors favoured different methodologies. While industry and government bodies emphasised physiological research on stress and pain, the small but growing community of applied ethologists profited from welfare organisations' funding taboos and growing interest in 'normal' behaviour, 'natural' habitats, and animal preferences.

${ }^{151}$ TNA MAF 369/240 FAWAC, Minutes of 17th Meeting (27.01.1978), 3; FACT Files, DB, Unmarked Blue Ryman Folder, Ruth Harrison-FACT-Opinion (19.04.1978).

${ }^{152}$ TNA MAF 369/272 House of Commons Agriculture Committee-Replies to Questions Enclosed with Dr Jack's Letter of 03.02.1981 to Mr Shillito, 3-4.

${ }^{153}$ Ryder, Animal Revolution, 184.

${ }^{154}$ David Fraser, "Understanding Animal Welfare," S1. 
However, disagreement on how to weight indicators dampened hopes for universal welfare standards. Fifteen years after Animal Machines' rallying cry for farm animal welfare, nobody seemed to be able to agree on how new standards should look and who had the authority to define them.

For Harrison, her 12 years within FAWAC and 6 years within the RSPCA Council had proven to be a mixed blessing. On the one hand, membership in both bodies had guaranteed her political influence even after memories of her bestseller began to fade. On the other hand, her work in a notoriously indecisive government committee exposed her to criticism from younger Reform Group members, while her leaking of the BFSS letter left her isolated among RSPCA traditionalists. After failing to secure a re-election to the RSPCA Council in 1975 and losing influence on the public 'frontstage' of activist politics, Harrison refocused on her 'backstage' government work and intensified her ties to animal welfare scientists. Her strategy of commissioning targeted research via FACT, and delaying FAWAC decisions helped prevent the enactment of weak welfare codes. However, without coordinated 'frontstage' pressure tactics like the ones she had employed around 1970, it also failed to produce meaningful new national codes. Estranged from the new RSPCA Council, isolated in an increasingly divided FAWAC, and forced to file personal bankruptcy in 1975, the second half of the 1970s marked an ebb in Harrison's activist career. For a while, it seemed as though there was no longer any place for the almost 60 -year-old in the brave new world of animal politics she had helped to unleash.

Open Access This chapter is licensed under the terms of the Creative Commons Attribution 4.0 International License (http://creativecommons.org/licenses/ by $/ 4.0 /)$, which permits use, sharing, adaptation, distribution and reproduction in any medium or format, as long as you give appropriate credit to the original author(s) and the source, provide a link to the Creative Commons licence and indicate if changes were made.

The images or other third party material in this chapter are included in the chapter's Creative Commons licence, unless indicated otherwise in a credit line to the material. If material is not included in the chapter's Creative Commons licence and your intended use is not permitted by statutory regulation or exceeds the permitted use, you will need to obtain permission directly from the copyright holder. 